\title{
Efficacy of Yoga Nidra vs Supine Relaxation Technique on Depression, Anxiety, Insomnia in frontline COVID-19 Health Care Workers: A Randomized Controlled Trial
}

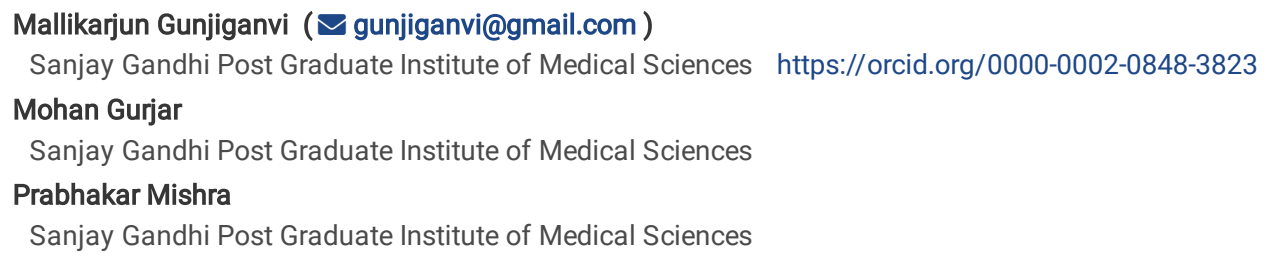

\section{Research Article}

Keywords: Yoga, Yoga Nidra, Supine Relaxation Technique, Meditation, Mindfulness, Depression, Anxiety, Insomnia, Randomized Trial, COVID-19

Posted Date: May 11th, 2021

DOI: https://doi.org/10.21203/rs.3.rs-486904/v1

License: @ (i) This work is licensed under a Creative Commons Attribution 4.0 International License. Read Full License 


\section{Abstract \\ Background}

Mental health disturbances have been well documented due to COVID-19 pandemic. There was surge in literature about use of various Mind Body Therapies during pandemic to curb these disturbances. But none have been studied to prospectively during COVID-19 pandemic. Hence, present study was planned to evaluate the efficacy of Yoganidra in frontline Health care workers (HCW) during pandemic using online and digital tools.

\section{Methods}

This open label randomized trial consisting of 2 arms (Yoganidra and Supine Relaxation technique [SRT]) was conducted at Level- III COVID care centre involving dedicated frontline HCWs. Online YouTube digital platform was used deliver the respective intervention to study participants. Daily reminders were sent using digital social media. Each intervention lasted for 30min a day. Participants completing > 9 days of practice were included for analysis. Primary outcome was changes in scores of Physical Health Quality (PHQ)-9, Generalized Anxiety Score (GAD)-7, Insomnia Severity Index (ISI) scale. Secondary outcomes were rate of recruitment, days of intervention practice, satisfaction of digital contents. Statistical analysis was carried out using SPSS v.23.

\section{Results}

Of $139 \mathrm{HCWs}$ contacted, $79 \mathrm{HCWs}$ (40 in SRT and 39 in Yoganidra) consented and were recruited into study. After withdrawal and incomplete practice days, 32 in SRT group and 30 in Yoganidra group were included for final analysis. Demographics and pre-intervention scores of PHQ-9, GAD-7, ISI were comparable at baseline. After completion of study, there were significant reduction in scores of PHQ-9, GAD-7 and ISI in Yoganidra 0.002 vs $0.064,<0.001$ vs $0.123,<0.001$ vs 0.828 respectively and effect size was $0.041,0.013$ and 0.024 respectively compared to SRT group. Recruitment rate was $56.8 \%, 78 \%$ of participants completed $>9$ days of practice and $100 \%$ satisfaction among participants.

\section{Conclusion}

Yoganidra significantly reduces depression, anxiety and insomnia scores among frontline COVID HCWs compared to SRT using virtual session platform. It is also feasible to conduct the virtual sessions of Yoga Nidra using digital platform.

\section{Trial Registration:}

Clinical Trials Registry of India REF/CTRI/2020/07/026609, (ctri.nic.in/clinicaltrials/login.php, number REF/CTRI/2020/07/026609)

\section{Background:}

Coronavirus disease 2019 (COVID-19) is a severe acute respiratory infection COVID-19 started as an outbreak in Wuhan, Hubei Province of China spread rapidly globally to become pandemic with several countries imposing lockdown [1]. COVID-19 is a highly contagious disease and has a widely varying spectrum of clinical presentations most common being respiratory symptoms [2]. But emotional, psychological problems like depression, anxiety, stress, and insomnia in both patients and all spectrum of health care providers are prevalent $[3,4]$. The fear of rapid spread combined with the active and passive quarantine of patients from family and health care workers during active duty, and changes in circadian during duty with rapid shift changes, lack of adequate personal protective equipment, improper self-care, inadequate stay and food during isolation, infrequent and inadequate interactions and communications with family and friends (the need of modern/digital era), less time and no space for recreational activities further exacerbate the emotional, psychological problems $[5,6,7]$. These mental health disturbances have been well documented in the COVID literature $[6,7,8,9]$. To cope with emotional, behavioral, and psychological problems various traditional, complementary, and integrative medicines have been extensively reviewed for COVID-19 crisis psychosomatic symptoms with sound scientific evidence. Various Mind-Body Techniques (MBT) including exercise, relaxations, meditation, stress regulation interventions, mindfulness, Qi Gong, Tai Chi, Tai Chi Qi Gong, Therapeutic touch, Transcendental Meditation, mindful Yogic practices have been used in the treatment of emotional and psychological problems like post-traumatic stress disorders, depression, and behavior management $[9,10,11,12,13,14,15,16]$.

Yoga, a form of MBT is an ancient Indian practice, induces cessation of thought waves in the mind. Yoga includes various yogic pranayamas (breath control exercises), yogic asanas (Yoga postures), and meditation or relaxation with considerable variability across different schools of Yoga and Yoga Nidra. Yoga Nidra (state of yogic sleep) is a dynamic state of consciousness between waking and sleeping, like the "going-to-sleep" stage and it involves a systematic method of inducing complete physical, mental and emotional relaxation. The term Yoga Nidra is derived from two Sanskrit words, Yoga meaning union or onepointed awareness, and Nidra means sleep. During the practice of Yoga Nidra, one appears to be asleep, but the consciousness is functioning at a deeper level of awareness. For this reason, Yoga Nidra is often referred to as the state of psychic sleep or deep relaxation with inner awareness. In this threshold state between sleep and wakefulness, contact with the subconscious and unconscious dimensions occurs spontaneously [17, 18].

Various MBTs including Yoga are known to control the central nervous system directly or indirectly by invoking the whole body, peripheral neural connections, higher neural pathways, and alterations in genomic, intracellular, and cytoplasmic neurotransmitters in the central nervous system, thereby resulting in calmness, de-stress, relief of anxiety, recovery from depression and help in regulating circadian rhythm [19, 20, 21]. Yoga and Yoga Nidra have been used as successful alternative therapy for both recent and long-standing psychological disturbances, anxiety, insomnia, post-traumatic stress disorder, and overall 
general wellbeing in various patient populations [19, 20, 21, 22, 23, 24]. Yoga therapy as an alternative form of therapy for behavioral modification is safer without any known complications directly related to it [25]. Considering the beneficial effects and non-availability of controlled trials evaluating the degree of feasibility and efficacy of various MBTs in COVID-19 health care professionals, the Yoganidra study was planned.

\section{Methods:}

This prospective open-label randomized controlled study was carried out at the super-specialty referral center (Level III covid care center) from Sept 2020 through Feb 2021. The study was approved by Institutional Ethics Committee [IEC code: 2020-165-IP-EXP-22]. The trial was registered at the Clinical Trials Registry of India [REF/CTRI/2020/07/026609]. Frontline COVID health care workers (HCW) on COVID-19 duty (Physicians, Residents, and Staff Nurses) during the study period, agreeing to participate were included in the study.

\section{Inclusion and Exclusion criteria}

Frontline HCWs with the knowledge of the English language, who were involved in the active care of COVID-19 patients and willing to participate in the study were included in the study. HCWs who became symptomatic of COVID-19 during the study period needing hospitalization and HCWs not practicing interventions after randomization were excluded from the study.

\section{Sample size calculation}

Sample size was calculated taking into consideration that, Supine Relaxation Technique (SRT) and Yoganidra would reduce the Depression, Anxiety, and Insomnia in frontline HCWs with an assumed reduction in SRT and Yoganidra of $25 \%$ and $60 \%$ respectively. At minimum two-sided $95 \%$ confidence interval and $80 \%$ power of the study, the estimated sample size in each of the two groups was 27 . After adjusting $20 \%$ loss to follow up, finally, we targeted randomizing $33 \mathrm{HCWs}$ in each of the two groups. However, patients were continuously recruited further even after completion of sample size, and the same randomization table was repeated. The sample size was estimated using free software G*Power 3.1.9.2.

\section{Recruitment and randomization}

By taking into consideration of Covid duty roster of frontline HCWs, they were contacted telephonically and briefed in detail about the study including objectives and methodology one day before their scheduled duty for the COVID-19 health center. Randomization was performed using a computer-generated list of random numbers and allocation was followed in sequentially numbered sealed envelopes. The block randomization method was used to draw the random number between 1 to 66 with 33 in each group where seed number (101357327907440) with block size 6 were used. The envelopes were opened by a person who was not involved in the study and participants were allotted to particular groups in sequence. Health care workers were randomly allocated into the SRT group or Yoga Nidra.

\section{Intervention}

Since HCWs were dealing with a highly contagious virus, and strict isolations and social distancing were mandatory to curb the disease spread, it was not possible to deliver the content in physical mode and common sessions were not possible, the instructions for relevant sessions were practiced virtually using digital YouTube platform. Hence, all the participant HCWs were contacted telephonically, familiar social messaging applications were used and relevant participatory digital materials were given. All willing participants were given the electronic questionnaire consisting of demographics; Patient Health Questionnaire-9 (PHQ-9), Generalized Anxiety Disorder-7 (GAD-7) scale, and 7-item Insomnia Severity Index (ISI) scale, and responses were collected in online forms. After randomization to particular groups, relevant YouTube links (particular to the study arms) were delivered using a smartphone device. Participant HCWs were reminded twice daily for the entire duration of the study period for particular techniques and were asked to practice the relevant method at their convenience due to altered circadian and rapid shift changes nature of duties.

1. Group A / SRT (Supine Relaxation Technique) Group: In the Supine Relaxation Technique (a form of Mindfulness meditation), HCWs were asked to lie down in a supine position comfortably on the floor and were asked to listen to deep sleep music with eyes closed and relaxed for 30 min duration. A YouTube link containing the details about the 'Deep Sleep Music' (https://www.youtube.com/watch?v=FaRrq7cYu84) was sent to the participants [26].

2. Group B / Yoganidra Group: Yoganidra (which is a state of dynamic yogic sleep) is a state of consciousness between waking and sleeping. In this group, HCWs were asked to lie down in a supine position comfortably and were asked to listen to Yoga Nidra instructions with eyes closed and relaxed for 30 min duration. Video demonstration of Yoga Nidra (https://www.youtube.com/watch?v=R2GRhAFplkl) (by Swami Niranjanananda Saraswati - Beginners) of 30 minutes duration was used for practicing Yoga Nidra [27]. All participant HCWs were followed on daily basis for 15 days i.e., the duration of covid duty period.

\section{Completion of intervention}

Intervention was considered as complete when the participants completed at least 9 days of practice. Frontline HCWs not practicing interventions for a minimum of 9 days were excluded from the final analysis.

\section{Primary outcome}

Changes in scores of PHQ-9 scale, GAD-7 scale, and ISI scale measurements before and after completion of COVID duty.

Secondary outcomes were rate of recruitment and completion of study interventions; and satisfaction concerning accessibility of content through YouTube digital platform, the digital content, and interventions relevancy and recommendations to the peer group. 


\section{Data collection}

Changes in depression, anxiety, and insomnia scores were measured using the PHQ-9 scale [28], GAD-7 scale [29] and ISI score scales [30] respectively. These validated scales were copyright-free and were free to use and were available for download from the internet with instructions on measurement. PHQ-9 scale (range 0-27) was interpreted as Normal/minimal (0-4), Mild (5-9), Moderate (10-14), Moderately severe (15-19), and Severe (20-27) depression. GAD-7 (range 0-21) was interpreted as Normal/minimal (0-4), Mild (5-9), Moderate (10-14), Severe (15-21) anxiety. ISI scale (range 0-28) was interpreted as no clinically significant insomnia (0-7), Subthreshold insomnia (8-14), Moderate severity clinical insomnia (15-21), and Severe clinical insomnia (22-28). The Cut off scores for detecting symptoms of major depression, anxiety, insomnia were 10, 7, and 15 respectively. All data were self-reported by participants. Rate of recruitment, rate of completion of the intervention, and rate of satisfaction were noted. Satisfaction was measured using the accessibility of content through YouTube digital platform, the digital content, and relevancy using dichotomized questionnaires (Yes/ No).

\section{Statistical analysis}

Data were collected using Google forms and transferred into Microsoft Excel 2010. Continuous variables were presented in mean \pm standard deviation/median (Interquartile range or IQR). Between SRT and Yoga groups, means were compared using independent samples t-test whereas data presented in medians were compared by Mann Whitney $U$ test. To test the change in pre and post observation between continuous measurements, Wilcoxon signed rank test was used. Categorical variables were presented in frequency (\%) and compared by chi-squared test / Fischer's exact test. Cohen Effect size was calculated between the paired differences of the means detected for SRT and Yoga Nidra patients. P-value $<0.05$ was taken as statistically significant. Statistical package for social sciences version-23 (SPSS-23, IBM, Chicago, USA) used for data analysis.

\section{Results:}

A total of 139 health care workers were contacted during the study period. 93 health care workers expressed interest in participating in the study. After delivering all digital materials, only 79 consented to the study and were recruited. $40 \mathrm{HCWs}$ in the SRT group and 39 HCWS in the Yoganidra group were allocated sequentially using random number table. In each group, 4 participants withdrew from the study after providing consent. After excluding participants with $<9$ days of practice of interventions, a total of 62 patients ( 32 in the SRT group and 30 in the Yoganidra group) were analyzed and remaining excluded due to incomplete practices [Figure 1].

Demographic variables i.e., age, gender, marital status, health care role, job types, presence of children < 5 years old and pregnant women in the family, fear of self-infection, fear of carrying the infection to family, financial worries were compared between SRT and Yoganidra groups and no significant difference was observed between two groups ( $p>0.05$ ). Also, infection transmission awareness, infection prevention awareness and mental health care services received were comparable between the groups. It is worth noting that only $65.6 \%$ in the SRT group and $60 \%$ in the Yoganidra group received some form of mental health care services [Table 1].

Table 1. Demographic and Clinical Characteristics 


\begin{tabular}{|c|c|c|c|}
\hline Characteristic & $\begin{array}{l}\text { SRT Group } \\
(n=32)(\%)\end{array}$ & $\begin{array}{l}\text { Yoganidra group } \\
(\mathrm{n}=30)(\%)\end{array}$ & $\mathrm{p}$ value \\
\hline Age (years) (mean sd) & 31.856 .32 & 32.97 & 0.43 \\
\hline Gender (Male) & $21(65)$ & $19(63)$ & 0.85 \\
\hline Marital status (Married) & $18(56)$ & $19(63)$ & 0.57 \\
\hline Education & & & 0.45 \\
\hline Graduate & $4(12)$ & $6(16)$ & \\
\hline Post-graduate & $7(21)$ & $9(25)$ & \\
\hline Post-doctoral & $21(65)$ & $15(58)$ & \\
\hline Role as a health care worker & & & 0.69 \\
\hline Faculty & $3(9)$ & $5(16)$ & \\
\hline Resident & $28(87)$ & $24(70)$ & \\
\hline Nursing Staff & $1(3)$ & $1(3)$ & \\
\hline Job type & & & 0.74 \\
\hline Permanent & $11(34)$ & $9(30)$ & \\
\hline Temporary & $16(50)$ & $14(46)$ & \\
\hline Contractual & $5(15)$ & $7(23)$ & \\
\hline Earlier covid duty prior to recruitment (days) & $27(84)$ & $21(70)$ & 0.17 \\
\hline Family type & & & 0.56 \\
\hline Nuclear & $26(81)$ & $26(13)$ & \\
\hline Joint & $6(18)$ & $4(86)$ & \\
\hline \multicolumn{4}{|l|}{ Number of family members } \\
\hline Children $<5 y$ r old in family-yes & $6(18)$ & $8(26)$ & 0.45 \\
\hline Pregnant women in family-yes & 0 & $1(3)$ & 0.29 \\
\hline Infected family members - yes & 0 & $2(7)$ & 0.14 \\
\hline Fear of self-infection - yes & $18(56)$ & $19(63)$ & 0.57 \\
\hline Fear of family infection - yes & $24(75)$ & $19(63)$ & 0.32 \\
\hline Financial worries - yes & $12(37)$ & $11(37)$ & 0.62 \\
\hline \multicolumn{4}{|l|}{ Infection Transmission Awareness } \\
\hline \multicolumn{4}{|l|}{ Cough } \\
\hline Handshake & $30(93)$ & $30(100)$ & - \\
\hline Touch & $29(90)$ & $26(86)$ & \\
\hline In-animate Objects & $27(84)$ & $28(93)$ & \\
\hline Shared water & $24(75)$ & $20(67)$ & \\
\hline Shared food & $15(46)$ & $18(60)$ & \\
\hline Contaminated water & $15(46)$ & $18(60)$ & \\
\hline \multirow[t]{2}{*}{ Contaminated food } & $12(37)$ & $13(43)$ & \\
\hline & $12(37)$ & $13(43)$ & \\
\hline Infection Prevention Awareness & & & - \\
\hline \multicolumn{4}{|l|}{ Social distance } \\
\hline Hand hygiene & $32(100)$ & $29(96)$ & \\
\hline Facemask usage & $32(100)$ & $29(96)$ & \\
\hline Prevent close contact & $31(96)$ & $29(96)$ & \\
\hline Cover nose and mouth during cough and sneeze & $31(96)$ & $29(96)$ & \\
\hline Prevent spitting & $30(93)$ & $28(93)$ & \\
\hline
\end{tabular}




\begin{tabular}{|c|c|c|c|}
\hline & $28(87)$ & $28(93)$ & \\
\hline Mental Health Care Services received & $21(65)$ & $18(60)$ & - \\
\hline \multicolumn{4}{|l|}{ Friends } \\
\hline Family & $10(31)$ & $6(20)$ & \\
\hline Social media & $7(22)$ & $4(13)$ & \\
\hline Digital media & $13(40)$ & $8(26)$ & \\
\hline Print media & $6(18)$ & $5(16)$ & \\
\hline Psychologist counseling & $7(22)$ & $2(7)$ & \\
\hline \multirow[t]{2}{*}{ Psychiatrist counseling } & $1(3)$ & $2(7)$ & \\
\hline & 0 & $1(3)$ & \\
\hline
\end{tabular}

The distributions of depression, anxiety, and insomnia frequencies in frontline COVID HCWs have been shown in Table 2. In the SRT group, some form of depression, anxiety, and insomnia were present in 12, 12, and $11 \mathrm{HCW}$ respectively and in the Yoga Nidra group 10, 10, 11 HCWs respectively before the intervention. But after the intervention, frequencies of some form depression, anxiety, insomnia decreased to 11,10, 9 HCWs in the SRT group respectively and in the Yoganidra group to 6, 5, 3 HCWs respectively. 
Table 2

Distribution of changes in the frequency of PHQ-9, GAD-7, ISI Scale subgroups between Pre- and Post-Intervention as well as between the study groups

\begin{tabular}{|c|c|c|c|c|}
\hline Variables & Study Groups & & Pre-Intervention & Post-Intervention \\
\hline \multirow[t]{10}{*}{ PHQ-9, Depression } & SRT & Minimal & $20(67)$ & $21(66)$ \\
\hline & \multirow[t]{4}{*}{$(n=32)(\%)$} & Mild & $7(22)$ & $9(28)$ \\
\hline & & Moderate & $3(9)$ & $2(6)$ \\
\hline & & Mod Severe & $1(3)$ & 0 \\
\hline & & Severe & $1(3)$ & 0 \\
\hline & \multirow{5}{*}{$\begin{array}{l}\text { Yoga } \\
(n=30)(\%)\end{array}$} & Minimal & $20(66)$ & $24(80)$ \\
\hline & & Mild & $6(20)$ & $6(20)$ \\
\hline & & Moderate & $2(7)$ & 0 \\
\hline & & Mod Severe & $2(7)$ & 0 \\
\hline & & Severe & 0 & 0 \\
\hline \multirow[t]{8}{*}{ GAD-7, Anxiety } & SRT & Minimal & $20(6)$ & $22(69)$ \\
\hline & \multirow[t]{3}{*}{$(n=32)(\%)$} & Mild & $9(28)$ & $8(25)$ \\
\hline & & Moderate & $1(3)$ & $1(3)$ \\
\hline & & Severe & $2(6)$ & $1(3)$ \\
\hline & \multirow{4}{*}{$\begin{array}{l}\text { Yoga } \\
(n=30)(\%)\end{array}$} & Minimal & $20(67)$ & $25(84)$ \\
\hline & & Mild & $6(20)$ & $4(13)$ \\
\hline & & Moderate & $4(13)$ & $1(3)$ \\
\hline & & Severe & 0 & 0 \\
\hline \multirow[t]{8}{*}{ ISI Score, Insomnia } & SRT & Absent & $21(65)$ & $23(72)$ \\
\hline & \multirow[t]{3}{*}{$(n=32)(\%)$} & Subthreshold & $9(21)$ & $7(22)$ \\
\hline & & Mod severe & $1(3)$ & $1(3)$ \\
\hline & & Severe & $1(3)$ & $1(3)$ \\
\hline & \multirow[t]{3}{*}{ Yoga (\%) } & Absent & $23(77)$ & $27(90)$ \\
\hline & & Subthreshold & $6(20)$ & $3(10)$ \\
\hline & & Mod severe & $1(3)$ & 0 \\
\hline & $(n=30)$ & Severe & 0 & 0 \\
\hline
\end{tabular}

\section{Primary Outcome Measures}

There was a statistical improvement in Scores of PHQ-9, GAD-7, ISI scale in the Yoga Nidra group compared to the SRT group after completion of covid duty [Table 3, Fig. 2]. 
Table 3

Change in PHQ-9, GAD-7, ISI Scale scores between Pre- and Post-Intervention as well as between the study groups.

\begin{tabular}{|c|c|c|c|c|c|c|c|}
\hline \multirow[t]{2}{*}{ Variables } & \multirow[t]{2}{*}{ Study Groups } & \multirow[t]{2}{*}{ Pre-Intervention } & \multirow[t]{2}{*}{ Post-Intervention } & \multirow[t]{2}{*}{$\begin{array}{l}\text { P-value } \\
\#\end{array}$} & \multicolumn{2}{|c|}{$\begin{array}{l}\text { Paired difference Mean } \pm \text { SD } \\
\text { [95\% Cl of Mean] }\end{array}$} & \multirow[t]{2}{*}{ P-value\$ } \\
\hline & & & & & Values & Effect size & \\
\hline \multirow[t]{6}{*}{ PHQ-7, Depression } & \multirow{3}{*}{$\begin{array}{l}\text { SRT } \\
(n=32)\end{array}$} & $5.68 \pm 4.73$ & $4.34 \pm 2.90$ & - & $1.34 \pm 3.97$ & 0.20 & 0.041 \\
\hline & & & & & {$[-0.09,2.78]$} & & \\
\hline & & $4(3,6)$ & $3(3,5)$ & 0.064 & - & & \\
\hline & \multirow{3}{*}{$\begin{array}{l}\text { Yoga } \\
(n=30)\end{array}$} & $5.17 \pm 4.25$ & $3.03 \pm 2.40$ & - & $2.13 \pm 3.85$ & & \\
\hline & & & & & {$[0.70,3.57]$} & & \\
\hline & & $4(3,6)$ & $2(1.75,4)$ & 0.002 & - & & \\
\hline \multirow[t]{6}{*}{ GAD-7, Anxiety } & \multirow{3}{*}{$\begin{array}{l}\text { SRT } \\
(n=32)\end{array}$} & $4.84 \pm 3.94$ & $4.03 \pm 3.56$ & - & $0.81 \pm 2.93$ & 0.62 & 0.013 \\
\hline & & & & & {$[-0.25,1.87]$} & & \\
\hline & & $3.5(2,6.75)$ & $3(2,5.75)$ & 0.123 & - & & \\
\hline & \multirow{3}{*}{$\begin{array}{l}\text { Yoga } \\
(n=30)\end{array}$} & $4.93 \pm 3.27$ & $2.33 \pm 2.56$ & - & $2.60 \pm 2.89$ & & \\
\hline & & & & & {$[1.52,3.68]$} & & \\
\hline & & $4(3,7)$ & $2(0,4)$ & $<0.001$ & - & & \\
\hline \multirow[t]{6}{*}{ ISI Score, Insomnia } & \multirow{3}{*}{$\begin{array}{l}\text { SRT } \\
(n=32)\end{array}$} & $6.09 \pm 5.37$ & $5.93 \pm 5.95$ & - & $0.15 \pm 5.53$ & 0.63 & 0.024 \\
\hline & & & & & {$[-1.84,2.15]$} & & \\
\hline & & $4(2,9.5)$ & $4(2,8)$ & 0.828 & - & & \\
\hline & \multirow{3}{*}{$\begin{array}{l}\text { Yoga } \\
(n=30)\end{array}$} & $6.10 \pm 3.53$ & $3.03 \pm 2.88$ & - & $3.06 \pm 3.53$ & & \\
\hline & & & & & {$[1.75,4.39]$} & & \\
\hline & & $6(4,7.25)$ & $3(0,5)$ & $<0.001$ & - & & \\
\hline \multicolumn{8}{|c|}{ Data presented in Mean \pm Standard deviation / Median (Q1, Q3). } \\
\hline \multicolumn{8}{|c|}{$\begin{array}{l}\text { Between Pre-Post comparisons, by \#Wilcoxon signed-rank test. Effect size calculated for the mean difference between Meditation and Yoga. The } \\
\text { difference between SRT and yoga was compared by } \$ \text { Mann Whitney U test. } \mathbf{p}<0.05 \text { significant. }\end{array}$} \\
\hline
\end{tabular}

There was a statistically significant improvement in the PHQ-9 scores as evidenced by the decrease in depression score in the Yoga Nidra group compared to the SRT group ( $p=0.002$ vs $p=0.064$ ) after the COVID duty period. However, the percentage improvement changes between SRT and Yoganidra groups as measured by the Effect Size though small 0.20 (paired difference $1.34 \pm 3.97$ (SRT) vs $2.13 \pm 3.85$ (Yoganidra)) but was statistically more pronounced in Yoganidra group $\mathrm{p}=0.041$.

Anxiety scores showed statistically significant improvement in the Yoga Nidra group as evidenced by the reduction in anxiety score compared to the SRT group ( $p<0.001$ vs $p=0.123$ ). The Effect Size was large at 0.62 (paired difference $0.81 \pm 2.93($ SRT) vs $2.60 \pm 2.89$ (Yoganidra)) and was statistically significant at $p=0.013$.

There was a statistically significant reduction in Insomnia scores in the Yoga Nidra group compared to the SRT group $(p<0.001$ vs $p=0.828)$. The Effect Size was also large at 0.63 (paired difference $0.15 \pm 5.53$ (SRT) vs $3.06 \pm 3.53$ (Yoganidra)) and was statistically significant at $p=0.024$.

\section{Secondary Outcomes}

Of 139 covid HCWs contacted for study recruitment, only $79 \mathrm{HCW}$ could be recruited i.e., $56.8 \%$ recruitment rate was possible during the study period. Only $78 \%$ of recruited participants completed $>9$ days of intervention. All recruited HCWs expressed $100 \%$ satisfaction concerning accessibility of content through YouTube digital platform, the digital content, and interventions relevancy. All participants recommended the requirement of these interventions to the peer groups.

\section{Discussion:}

In this trial of Yoganidra vs SRT, there was a significant reduction in depression, anxiety, and insomnia scores among COVID HCWs in the Yoganidra group compared to the SRT group at the end of the COVID duty period of 15 days. This study also demonstrated the feasibility of the effective utilization of virtual sessions of MBTs through available digital platforms.

Before conducting this trial, the literature review didn't yield any published results of trials involving Yoganidra as a non-pharmacological alternativecomplementary therapeutic approach for depression, anxiety, insomnia, or stress in COVID HCWs. However, there was a vast surge in the reviewed literature 
about the use of various MBTs during the COVID pandemic. Though each technique was supported by the available scientific evidence, none were formally studied on the COVID-19 psychosomatic crisis symptomatology.

There were alarming reports of the development of COVID-19 related to depression, anxiety, insomnia, and distress from the Chinese mainland both in frontline $\mathrm{HCW}$ and the public $[7,8]$. More than $50 \%$ of frontline HCWs including the public were affected by varying severity of depression, anxiety, insomnia, and distress [6, 7]. In our study involving only frontline HCW, there was some form of depression, anxiety, and insomnia in approximately $35 \%$ combined in both the groups. In the present study, factors known to cause or exaggerate the psychological symptoms in acute stress situations such as marital status, education level, the role of health care workers, type of job profile, earlier covid duties, family type (joint/ nuclear), number of family members; the presence of children, pregnant women and any infected members in the family; and fear of self-infection and carrying the infection to family were also included. Other potential factors like awareness about infection transmission and prevention were also studied.

The most significant factor for infection control as well as exacerbation of mental and psychological problems was 'isolation' during the pandemic. Delivery of various therapies including behavioural therapy and MBTs was a herculean task. But, to address this issue, many treatment modules, mental health care models, and strategies were developed to overcome the therapeutic barrier. These included psychological response team, technical support team for psychological intervention, psychological/social/psychiatric intervention team and psychological front-line teams, multiple virtual/digital platforms, digital modules, digital learning packages, and telemedicine services [31, 32, 33, 34]. Given the fact that COVID and isolations were increasing the psychological problems among HCWs and the public, there was a drive in the use of various MBTs [35]. In one cross-sectional survey, $59.6 \%$ of survey respondents reported practice of Yoga during lockdown to alleviate stress and improve well-being [36].

Given the exponential costs of COVID health care services, human resources, and barriers in delivering the various behavioural therapies including the difficult access to mental health care professionals, simple Yoga protocols may play a role in the management of COVID psychological problems. Presently a randomized trial using Sudarshan Kriya is being studied [37]. Presently, the National University of Natural Medicine is recruiting volunteers for the feasibility study of digital delivery of Yoganidra in anxiety and sleep [38].

With the COVID-19 pandemic, the world witnessed rapid adaptation to virtual mode. It made some worldly advancements in the digital area. Adaptions to virtual sessions of Yoga and other MBTs for effective on-demand delivery with time being not determining factor helped many MBTs seekers. Various alternative complementary schools started delivering virtual sessions of MBTs including different Yoga Protocols. Benefits of the virtual era combined with ease of administration of various tailored MBTs may play role in the management of various psychological problems faced by COVID HCWs.

There were few strengths to this study. This was the first study evaluating the MBTs (Yoga Nidra) in frontline COVID-19 HCW. This study showed the effective use of digital technology and delivery of content effectively using available digital platforms. This study showed the feasibility of virtual MBTs. However, there were certain limitations. The rate of recruitment was less because the open nature of study participants expressed interest in the Yoga Nidra rather than SRT. In this study, all HCW irrespective the basal depression, anxiety, and insomnia were recruited. The study can be made more robust by including only those HCW with some form of depression, anxiety, and insomnia. Nevertheless, this study showed feasibility, good recruitment, and a proof of concept of virtual yoga through the digital platform and paved the way for more robust, large-scale, multicentric intervention.

\section{Conclusions:}

This study of Virtual Yoganidra showed the benefits of improvement in depression, anxiety, and insomnia. This study gave proof of concept and can help in wide adaptions of this particular protocol for various HCWs suffering from psychological problems and hence can help in immune-boosting. It can also be personalized for individual integrated care. Further studies need to be focused on recruiting those HCWs suffering from psychological problems.

\section{Abbreviations:}

COVID-19

Corona Virus Disease 2019

MBT

Mind Body Therapy

HCW

Health Care Worker

SRT

Supine Relaxation Group

PHQ

Physical Health Questionnaire

GAD

Generalized Anxiety Disorder

ISI

Insomnia Severity Index

IQR

Interquartile Range

\section{Declarations:}




\section{Ethics Approval and Consent to participate:}

We hereby state that a review of the protocol by the individual Institute Ethics Committee (IEC) has been done. Details of final approval by IEC is as follows.

Sanjay Gandhi Post Graduate Institute of Medical Sciences, Lucknow, India.

IEC code: 2020-165-IP-EXP-22.

Consent for publication: Not applicable.

\section{Availability of data and materials:}

The datasets used and/or analysed during the current study are available from the corresponding author on reasonable request.

\section{Competing interests:}

The authors declare that they have no competing interests.

\section{Funding:}

No Financial support is received.

\section{Authors' contributions:}

MG1: Chief Investigator, conceived the study concept, protocol development, lead methodologist, data collection, interpretation, manuscript first draft. MG2: contributed to study protocol, development of proposal, final manuscript revision, PM: Statistical design, Analysis. All authors read and approved the final manuscript.

Acknowledgements: Not applicable

\section{References:}

1. WHO Director-General's opening remarks at the media briefing on COVID-19-11. March 2020. https://www.who.int/dg/speeches/detail/who-directorgeneral-s-opening-remarks-at-the-media-briefing-on-covid-19--11-march-2020 Accessed on 05/05/2020.

2. Fu L, Wang B, Yuan T, Chen X, Ao Y, Fitzpatrick T, Li P, Zhou Y, Lin YF, Duan Q, Luo G, Fan S, Lu Y, Feng A, Zhan Y, Liang B, Cai W, Zhang L, Du X, Li L, Shu Y, Zou H. Clinical characteristics of coronavirus disease 2019 (COVID-19) in China: A systematic review and meta-analysis. J Infect. 2020 Jun;80(6):65665. DOI:10.1016/j.jinf.2020.03.041

3. Inchausti F, Macbeth A, Hasson-Ohayon I, Dimaggio G. Psychological Intervention and COVID-19: What We Know So Far and What We Can Do. J Contemp Psychother. 2020 May 27:1-8. DOI: 10.1007/s10879-020-09460-w.

4. Taylor WD, Blackford JU. Mental Health Treatment for Front-Line Clinicians During and After the Coronavirus Disease 2019 (COVID-19) Pandemic: A Plea to the Medical Community. Ann Intern Med. 2020 Oct;6(7):574-5. DOI:10.7326/M20-2440. 173 ) .

5. van Doremalen N, Bushmaker T, Morris DH, et al. Aerosol and surface stability of SARS-CoV-2 as compared with SARS-CoV-1. N Engl J Med. 2020 Apr;16(16):1564-7. 382(.

6. Lai J, Ma S, Wang Y, et al. Factors Associated With Mental Health Outcomes Among Health Care Workers Exposed to Coronavirus Disease 2019. JAMA Netw Open. 2020;3(3):e203976. doi:10.1001/jamanetworkopen.2020.3976. Published 2020 Mar 2.

7. Kang L, Ma S, Chen M, et al. Impact on mental health and perceptions of psychological care among medical and nursing staff in Wuhan during the 2019 novel coronavirus disease outbreak: A cross-sectional study [published online ahead of print, 2020 Mar 30]. Brain Behav Immun. 2020. doi:10.1016/j.bbi.2020.03.028.

8. Santarone K, McKenney M, Elkbuli A. Preserving mental health and resilience in frontline healthcare workers during COVID-19. Am J Emerg Med. 2020 Jul;38(7):1530-1. DOI:10.1016/j.ajem.2020.04.030.

9. Brooks SK, Webster RK, Smith LE, et al. The psychological impact of quarantine and how to reduce it: rapid review of the evidence. Lancet. 2020;395(10227):912-20. doi:10.1016/S0140-6736(20)30460-8.

10. Lancaster CL, Teeters JB, Gros DF, Back SE. Posttraumatic Stress Disorder: Overview of Evidence-Based Assessment and Treatment. J Clin Med. 2016 Nov 22;5(11):105. DOI: 10.3390/jcm5110105. PMID: $27879650 ;$ PMCID: PMC5126802.

11. Dzierzewski JM, O'Brien EM, Kay D, McCrae CS. Tackling sleeplessness: psychological treatment options for insomnia in older adults. Nat Sci Sleep. 2010 Apr;1:2:47-61. DOI:10.2147/NSS.S7064. PMID: 22323897; PMCID: PMC3273867.

12. Avasthi A, Sahoo S, Grover S. Clinical Practice Guidelines for Cognitive Behavioral Therapy for Psychotic Disorders. Indian J Psychiatry. 2020 Jan;62(Suppl 2):S251-S262. DOI: 10.4103/psychiatry.IndianJPsychiatry_774_19. Epub 2020 Jan 17. PMID: 32055067; PMCID: PMC7001360.

13. Seppälä EM, Nitschke JB, Tudorascu DL, Hayes A, Goldstein MR, Nguyen DT, et al. Breathing-based meditation decreases posttraumatic stress disorder symptoms in U.S. military veterans: a randomized controlled longitudinal study. J Trauma Stress. 2014;27:397-405

14. Tillu G, Chaturvedi S, Chopra A, Patwardhan B. Public Health Approach of Ayurveda and Yoga for COVID-19 Prophylaxis. J Altern Complement Med. 2020 May;26(5):360-4. DOI:10.1089/acm.2020.0129 
15. Portella CFS, Ghelman R, Abdala CVM, Schveitzer MC. Evidence map on the contributions of traditional, complementary and integrative medicines for health care in times of COVID-19. Integr Med Res. 2020 Sep;9(3):100473. DOI: 10.1016/j.imr.2020.100473.

16. Seifert G, Jeitler M, Stange R, Michalsen A, Cramer H, Brinkhaus B, Esch T, Kerckhoff A, Paul A, Teut M, Ghadjar P, Langhorst J, Häupl T, Murthy V, Kessler CS. The Relevance of Complementary and Integrative Medicine in the COVID-19 Pandemic: A Qualitative Review of the Literature. Front Med (Lausanne). 2020 Dec;11:7:587749. doi:10.3389/fmed.2020.587749.

17. Saraswati SS. Bihar School of Yoga. In: Yoganidra. Munger: Yoga Publications Trust; 1998.

18. Saraswati SS. Dynamics of Yoga. The Foundations of Bihar Yoga. 2nd ed. Munger: Yoga Publications Trust (Bihar School of Yoga); 2002.

19. Girodo M. Yoga meditation and flooding in the treatment of anxiety neurosis. J Behav Ther Exp Psychiat. 1974;5:157-60.

20. Kiecolt-Glaser JK, Christian L, Preston H, et al. Stress, inflammation, and Yoga practice. Psychosom Med. 2010;72:113-21.

21. Brown RP, Gerbarg PL. Sudarshan Kriya yogic breathing in the treatment of stress, anxiety, and depression: part I-neurophysiologic model. J Altern Complement Med. 2005;11:189-201.

22. Simon NM, Hofmann SG, Rosenfield D, Hoeppner SS, Hoge EA, Bui E, Khalsa SBS. Efficacy of Yoga vs Cognitive Behavioral Therapy vs Stress Education for the Treatment of Generalized Anxiety Disorder: A Randomized Clinical Trial. JAMA Psychiatry. 2021 Jan 1;78(1):13-20. DOI: 10.1001/jamapsychiatry.2020.2496.

23. Yung PMB, Fung MY, Chan TMF, Lau BWK. Relaxation training methods for nurse managers in Hong Kong: a controlled study. International Journal of Mental Health Nursing. 2004;13:255-61. doi:10.1111/j.1445-8330.2004.00342.x.

24. Stankovic L. Transforming trauma: a qualitative feasibility study of integrative restoration (iRest) Yoganidra on combat-related post-traumatic stress disorder. Int J Yoga Ther. 2011;21:23-37.

25. Cramer H, Ward L, Saper R, Fishbein D, Dobos G, Lauche R. The Safety of Yoga: A Systematic Review and Meta-Analysis of Randomized Controlled Trials. Am J Epidemiol. 2015 Aug 15;182(4):281 - 93. DOI: 10.1093/aje/kwv071.

26. Relaxing music. 30-Minute-Deep Sleep Music: Calming Music, Relaxing Music, Soothing Music. https://www.youtube.com/watch?v=FaRrq7cYu84, available at YouTube digital platform, accessed on Apr 15, 2020. Cited on Apr 15, 2020.

27. Yoga Nidra by Swami Niranjanananda Saraswati (Beginners). https://www.youtube.com/watch?v=R2GRhAFplkl, available at YouTube digital platform, accessed on Apr 15, 2020. Cited on Apr 15, 2020.

28. PHQ9 Copyright (C) Pfizer Inc. available at http://med.stanford.edu/fastlab/research/imapp/msrs/_jcr_content/main/accordion/accordion_content3/download_256324296/file.res/PHQ9\%20id\%20 Accessed on Apr 15, 2020. Cited on Apr 15, 2020.

29. Spitzer RL, Kroenke K, Williams JBW, Löwe B. A Brief Measure for Assessing Generalized Anxiety Disorder: The GAD-7. Arch Intern Med. 2006;166(10):1092-7. doi:10.1001/archinte.166.10.1092.

30. Morin CM, Belleville G, Bélanger L, Ivers $\mathrm{H}$. The insomnia severity index: psychometric indicators to detect insomnia cases and evaluate treatment response. SLEEP. 2011;34(5):601-8.

31. Braquehais MD, Vargas-Cáceres S, Gómez-Durán E, Nieva G, Valero S, Casas M, Bruguera E. The impact of the COVID-19 pandemic on the mental health of healthcare professionals. QJM. 2020 Jun 22:hcaa207. doi: 10.1093/qjmed/hcaa207. Epub ahead of print.

32. Hall DL, Millstein RA, Luberto CM, Perez GK, Park ER. Responding to COVID-19 Stress: Disseminating Mind-Body Resiliency Approaches. Glob Adv Health Med. 2020 Dec;1:9:2164956120976554. DOI:10.1177/2164956120976554.

33. Blake H, Bermingham F, Johnson G, Tabner A. Mitigating the Psychological Impact of COVID-19 on Healthcare Workers: A Digital Learning Package. Int J Environ Res Public Health. 2020 Apr 26;17(9):2997. DOI: 10.3390/ijerph17092997.

34. Kwon CY, Kwak HY, Kim JW. Using Mind-Body Modalities via Telemedicine during the COVID-19 Crisis: Cases in the Republic of Korea. Int J Environ Res Public Health. 2020 Jun 22;17(12):4477. DOI: 10.3390/ijerph17124477.

35. Jane Hart.Alternative and Complementary Therapies.Dec 2020.243- 245. http://doi.org/10.1089/act.2020.29298.jha.

36. Sahni PS, Singh K, Sharma N, Garg R. Yoga an effective strategy for self-management of stress-related problems and wellbeing during COVID19 lockdown: A cross-sectional study. PLoS One. 2021 Feb 10;16(2):e0245214. DOI: 10.1371/journal.pone.0245214.

37. Lai KSP, Watt C, lonson E, et al. Breath Regulation and yogic Exercise An online Therapy for calm and Happiness (BREATH) for frontline hospital and longterm care home staff managing the COVID-19 pandemic: A structured summary of a study protocol for a feasibility study for a randomised controlled trial. Trials. 2020 Jul;21(1):648. DOI: 10.1186/s13063-020-04583-w.

38. https://nunm.edu/research/studies/yoga-nidra-impact/ accessed on Mar 24, 2021, cited on Mar 24, 2021.

\section{Figures}




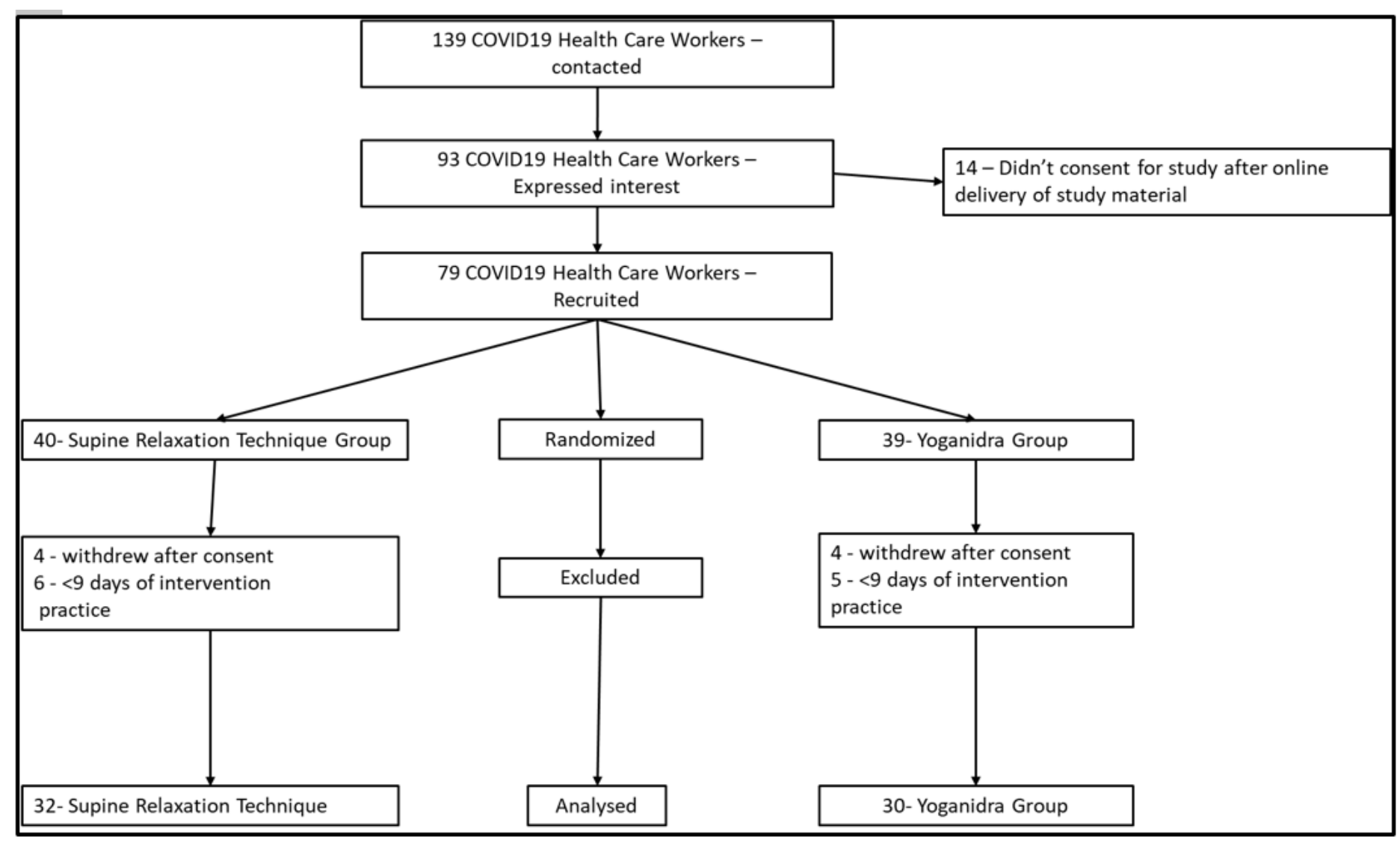

Figure 1

Consort Chart

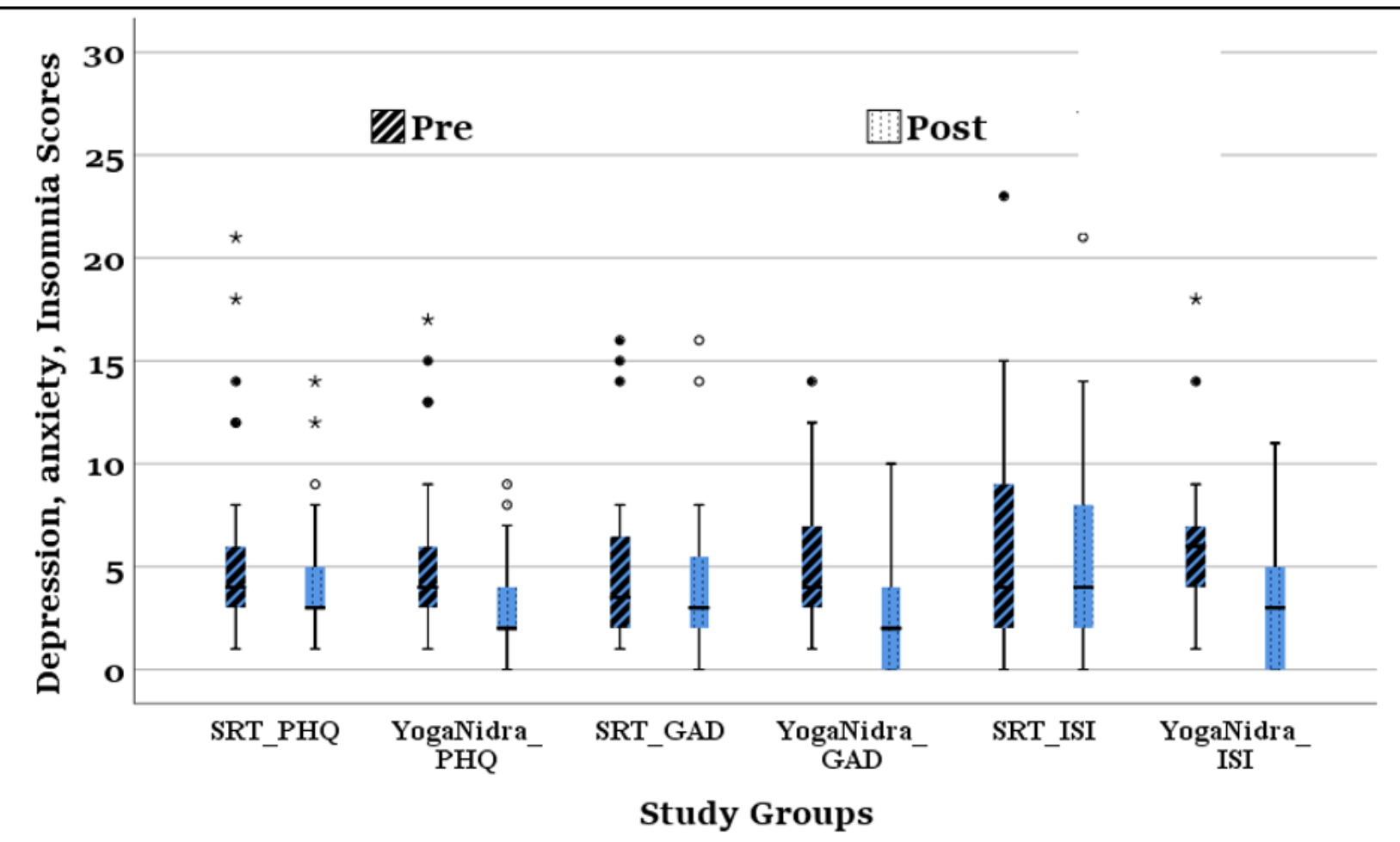

Figure 2

Change in Scores of PHQ-9, GAD-7, and ISI scale Pre-Post Intervention 
This is a list of supplementary files associated with this preprint. Click to download.

- TrialscompletedCONSORTchecklist.docx

Page $13 / 13$ 